\title{
The evolving role of hyaluronic acid fillers for facial volume restoration and contouring: a Canadian overview
}

This article was published in the following Dove Press journal:

Clinical, Cosmetic and Investigational Dermatology

27 September 2012

Number of times this article has been viewed

\section{Channy Muhn' \\ Nathan Rosen' \\ Nowell Solish ${ }^{2}$ \\ Vince Bertucci \\ Mark Lupin ${ }^{3}$ \\ Alain Dansereau ${ }^{4}$ \\ Fred Weksberg ${ }^{5}$ \\ B Kent Remington ${ }^{6}$ \\ Arthur Swift ${ }^{7}$ \\ 'Division of Dermatology, McMaster \\ University, Hamilton, Ontario, \\ ${ }^{2}$ Division of Dermatology, New \\ Women's College Hospital, \\ Toronto, Ontario, ${ }^{3}$ Department of Dermatology and Skin Science, University of British Columbia, \\ Vancouver, British Columbia, ${ }^{4}$ Private Practice, Repentigny, Québec, \\ ${ }^{5}$ Department of Medicine, University of Toronto, Toronto, Ontario, ${ }^{6}$ Private Practice, Calgary, Alberta, Canada; ${ }^{7}$ St Mary's Hospital, McGill University, Montréal, Québec, Canada}

\begin{abstract}
Recent advancements, including more versatile facial fillers, refined injection techniques and the adoption of a global facial approach, have contributed to improved patient outcome and increased patient satisfaction. Nine Canadian specialists (eight dermatologists, one plastic surgeon) collaborated to develop an overview on volume restoration and contouring based on published literature and their collective clinical experience. The specialists concurred that optimal results in volume restoration and contouring depend on correcting deficiencies at various layers of the facial envelope. This includes creating a foundation for deep structural support in the supraperiosteal or submuscular plane; volume repletion of subcutaneous fat compartments; and the reestablishment of dermal and subdermal support to minimize cutaneous rhytids, grooves and furrows. It was also agreed that volume restoration and contouring using a global facial approach is essential to create a natural, youthful appearance in facial aesthetics. A comprehensive non-surgical approach should therefore incorporate combining fillers such as high-viscosity, low-molecular-weight hyaluronic acid (LMWHA) for structural support and hyaluronic acid (HA) for lines, grooves and furrows with neuromodulators, lasers and energy devices.
\end{abstract}

Keywords: hyaluronic acid filler, volumizing, facial rejuvenation

\section{Introduction}

Soft-tissue fillers have become the mainstay for both volume restoration and beauty maximization in selected patients. The availability of a variety of safe volumizing products with excellent tissue-lifting capacity in Canada has provided Canadian aesthetic specialists the opportunity to pioneer and contribute many important techniques to this rapidly developing arena.

A group of nine Canadian medical specialists (eight dermatologists, one plastic surgeon) collaborated to review, evaluate and discuss their current volume restoration and contouring practices. The observations and recommendations made here reflect a consensus from practices of the authors based on their collective clinical experience with over ten thousand patients as well as published literature in the field.

\section{Background}

It has long been accepted that facial aging is the result of deterioration and descent of cutaneous structures due to downward gravitational pull, hormonal changes, photodamage and smoking, among others. ${ }^{1}$ However, skeletal remodeling and subcutaneous fat re-distribution and loss are now recognized as key elements responsible for the appearance of age. ${ }^{1}$
Correspondence: Channy Muhn

3305 Harvester Rd, Units 8-9

Burlington, ON L7N 3N2, Canada

Tel + I 9053369623

Fax +l 9053369625

Email drmuhn@dermetics.ca 
Loss of appropriate facial fullness and youthful appearance occurs in most areas of the face to varying degrees, including the periorbital, malar, forehead, temporal, glabellar, mandibular, mental and perioral zones. ${ }^{1}$ A recent study determined that facial subcutaneous fat is partitioned into multiple, independent anatomical compartments, which may age independently, resulting in abrupt contour changes between them. ${ }^{2}$

Re-establishing the integrity of these foundation structures through appropriate volume restoration and contouring has proven to be a highly effective means of harmonizing features, contours, proportions and balance associated with the youthful face. ${ }^{1}$

The incorporation of volumizing techniques into the nonsurgical armamentarium represented a significant advancement in the approach to rejuvenation. Previously, emphasis had been placed primarily on lines and wrinkles; this initial focus of rejuvenation was two-dimensional, being confined to line effacement and improvement of the tone and texture of the skin. However, by transitioning to a three-dimensional approach that also addresses volume loss in soft and bony tissues, aesthetic physicians are now better equipped to treat both cause and effect. ${ }^{3}$ The clinician has concurrently evolved into a global rejuvenator and beauty maximizer.

\section{Definition of volumizing and contouring}

The authors define the concept of volume restoration and contouring with injectable soft tissue fillers as a global, threedimensional approach to rejuvenation, with strict attention to aesthetic proportional ideals. It is not simply the addition of volume, but rather the proper aesthetic placement of product in appropriate amounts that will create excellent results in restoring a natural youthful appearance.
A fundamental principle behind optimizing volume restoration and contouring is to treat all levels of the facial envelope beginning with the establishment of deep structural support. Further refining by "chasing" individual lines and folds is still an important adjunct to maximize the results obtained. The comprehensive non-surgical approach of combining fillers and neuromodulators with lasers and energy devices should always be considered for optimizing patient outcome results in addition to patient satisfaction. Although collagen was previously considered the mainstay in reconstruction, it is no longer used in volume restoration by the Canadian group. The products chosen most frequently by the authors for volume restoration and contouring were a high-viscosity, low-molecular-weight hyaluronic acid (LMWHA) for structural support and high molecular weight hyaluronic acids (HAs) for lines, grooves and furrows.

\section{Soft tissue fillers for facial volume restoration}

In response to the development of safe new materials in facial aesthetics, as well as the prevailing cautious economic environment, there appears to be a major shift away from the more costly surgical to the less-expensive non-surgical procedures employing injectable products. ${ }^{4}$

Currently, there is a myriad of injectable fillers available beyond autologous fat for volume restoration and contouring procedures (see Table 1). The hyaluronic acid gels, used predominantly, are available in a range of viscosities, and can be tailored for applications at multiple tissue levels to correct both volume loss and structural failure. Other "volumizing" options include products formulated with calcium hydroxylapatite, polymethyl methacrylate and poly-L-lactic acid. ${ }^{4,5}$

Table I Five categories of facial filler approved by Health Canada

\begin{tabular}{|c|c|c|}
\hline Category & Agent & Duration $^{a}$ \\
\hline High-viscosity, low molecular weight hyaluronic acid (LMWHA) & Voluma (Allergan, Inc) & Long duration (up to 18 months) $)^{5,6}$ \\
\hline \multirow[t]{8}{*}{ Hyaluronic acid (HA) } & Juvéderm (Allergan, Inc) & Intermediate duration $(\sim 12 \mathrm{mo})^{6}$ \\
\hline & Restylane (Medicis Aesthetics) & Intermediate duration $(\sim 6 \mathrm{mo})^{4}$ \\
\hline & Perlane (Medicis Aesthetics) & \\
\hline & Teosyal (Clarion Medical & \\
\hline & Technologies) & \\
\hline & Esthelis (Anteis) & \\
\hline & Prevelle (Mentor) & \\
\hline & Revanesse (Prollenium Medical) & \\
\hline Calcium hydroxylapatite & Radiesse (Merz Aesthetics) & Intermediate duration $(\sim \mathrm{yr})^{7}$ \\
\hline Poly-L-lactic acid (PLLA) & Sculptra (Valeant) & Long duration (up to 18 months) ${ }^{8}$ \\
\hline Polymethyl methacrylate (PMMA) & Artefill (Artes Medical/suneva) & Permanent $(\sim 10 \text { years })^{4}$ \\
\hline Platelet-Rich Fibrin Matrix (PRFM) & Selphyl (Canderm) & Long duration (up to 18 months) \\
\hline
\end{tabular}

Note: a'Some authors have seen duration of action which is longer than the amounts selphyl (Canderm) listed above. 
The authors have reported that the recent addition of a high-viscosity, low molecular weight hyaluronic acid (LMWHA) to the volumizing armamentarium has resulted in significantly improved patient outcomes. This is a smooth consistency gel that is uniquely composed of a mix of low and high molecular weight HA. Compared to HA fillers with $100 \%$ high molecular weight, the LMWHA allows a combination of high cohesivity and viscosity. This property enables the LMWHA to retain its structure following a deep injection and makes it particularly well suited for facial volumizing and contouring. ${ }^{5}$

As a point of interest, while the term 'dermal filler' is still widely used, it is arguably not anatomically accurate. Facial fillers are frequently used at multiple levels beneath the dermis - sub-muscularly above the periosteum and in the subcutaneous plane.

\section{Ideal physical properties of facial fillers for volume restoration and contouring}

The authors concur that volume restoration with a facial filler should not be considered simply the installation of a product, but rather, the establishment of a harmonious relationship between a product and its surrounding tissue.

For obvious reasons of cost and convenience to the patient, facial fillers should have a reasonably long-lasting persistence of effect. However, as the topography of the face constantly changes with time, an effective volumizing agent needs to either adapt, be modified, or fade away - if not, the face will change and the implant will not, resulting in a potentially undesirable unnatural appearance. ${ }^{9}$

An ideal soft tissue filler should also provide an optimal balance of longevity, lifting capacity and ease of injection. ${ }^{10}$ In their collective experience, the authors have found the high-viscosity LMWHA to have this favorable blend of physical properties, making it well suited to reinforce and rebuild facial foundation structures.

In general, a higher degree of crosslinking makes an HA filler more resistant to enzymatic and free radical degradation, therefore increasing its longevity in the tissues. An increased ratio of cross linked HA in a gel also contributes to its viscosity or stiffness, which is quantified by the G Prime (G') variable. A higher G' gel is less likely to be displaced once injected under the skin, thereby resulting in more cohesivity and 'lift'. ${ }^{10}$ By the same token though, a higher G' product will require more extrusion force and be difficult to push through a needle. ${ }^{10,11}$
The high-viscosity LMWHA gel has the advantage of a higher ratio of effective crosslinking and resultant $G$ ' thus achieving a longer-lasting lift and cohesivity required for successful deep-injection volumization, without compromising the ease of injection. In a final homogenization process, gel particles are broken down to create a smooth-consistency formulation that flows easily on injection and is moldable for optimal contouring. ${ }^{10,11}$

The following constitute the ideal physical properties of facial fillers for volume restoration and contouring in order to achieve optimal patient outcomes:

- Lift capacity

- Ease of injection

- Malleability/sculptability

Additional important attributes include:

- Reversibility

- Intermediate duration

- Safety

- Patient satisfaction

- Natural looking

- Minimal patient discomfort

- Minimal patient downtime

- Predictability of performance

- Hypo-allergenic

\section{Facial anatomy}

For optimal outcomes, it is necessary for clinicians to have a thorough understanding of facial anatomy as well as an appreciation of the aesthetic ideal (see Figure 1). While a dexterous employment of proper injection technique is paramount, it is equally important to understand the aesthetic

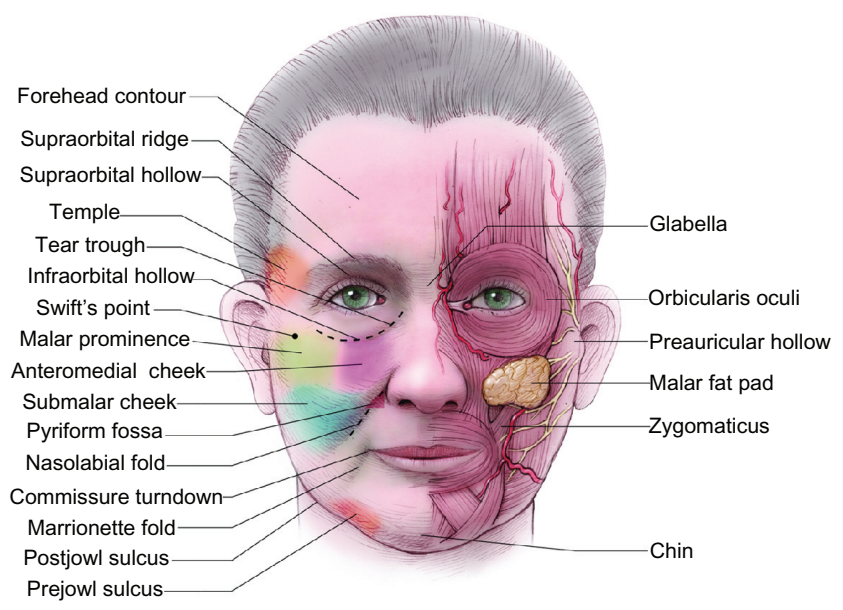

Figure I Clinical anatomic cosmetic units considered in soft tissue injections of the face.

Image provided by Allergan, Inc (Irvine, CA). 
principles of beauty; the harmonious inter-relationship of features that constitute a balanced and attractive face (see Figures 2 and 3). ${ }^{12}$

\section{Volume loss assessment scales}

In facial aesthetics, there is no single standardized, validated assessment scale. Some currently used scales include the James/Carruthers lipoatrophy severity scale, Meneghini classification and Raspaldo Volume Loss Staging I-V., ${ }^{5,13,14}$

In clinical studies, assessment scales are mandatory to measure changes from baseline in order to quantify the efficacy of a particular intervention or product. Most aesthetic physician/clinicians incorporate some sort of assessment scale in their clinical practices at both the assessment and treatment levels. Unfortunately, the majority of scales are subjectively based, and there is significant inter- and intraobserver variability. Furthermore, most currently-used scales were designed with minimal patient input, resulting in considerable bias, and did not account for ethnic nor cultural differences. The authors maintain that observation and palpation remain the tenets of proper assessment, and that ultimately it is the patient's outcome and level of satisfaction that are the true measure of a successful treatment.

\section{Patient identification and education}

Insufficient patient education remains a considerable obstacle to global facial enhancement by injection technique. Most

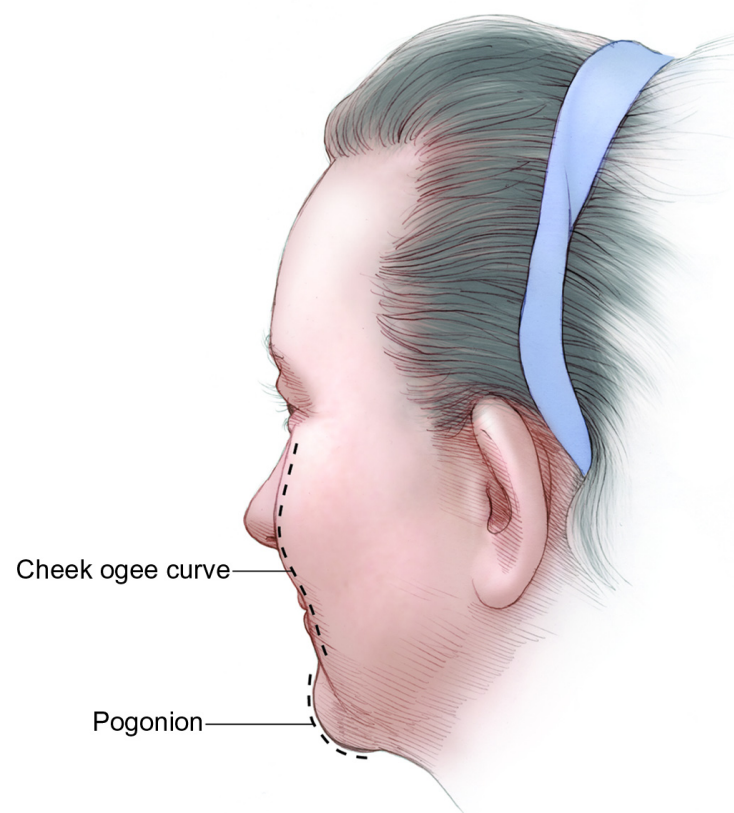

Figure 2 Posterior lateral view showing the cheek ogee curve and pogonion (chin projection).

Image provided by Allergan, Inc (Irvine, CA).
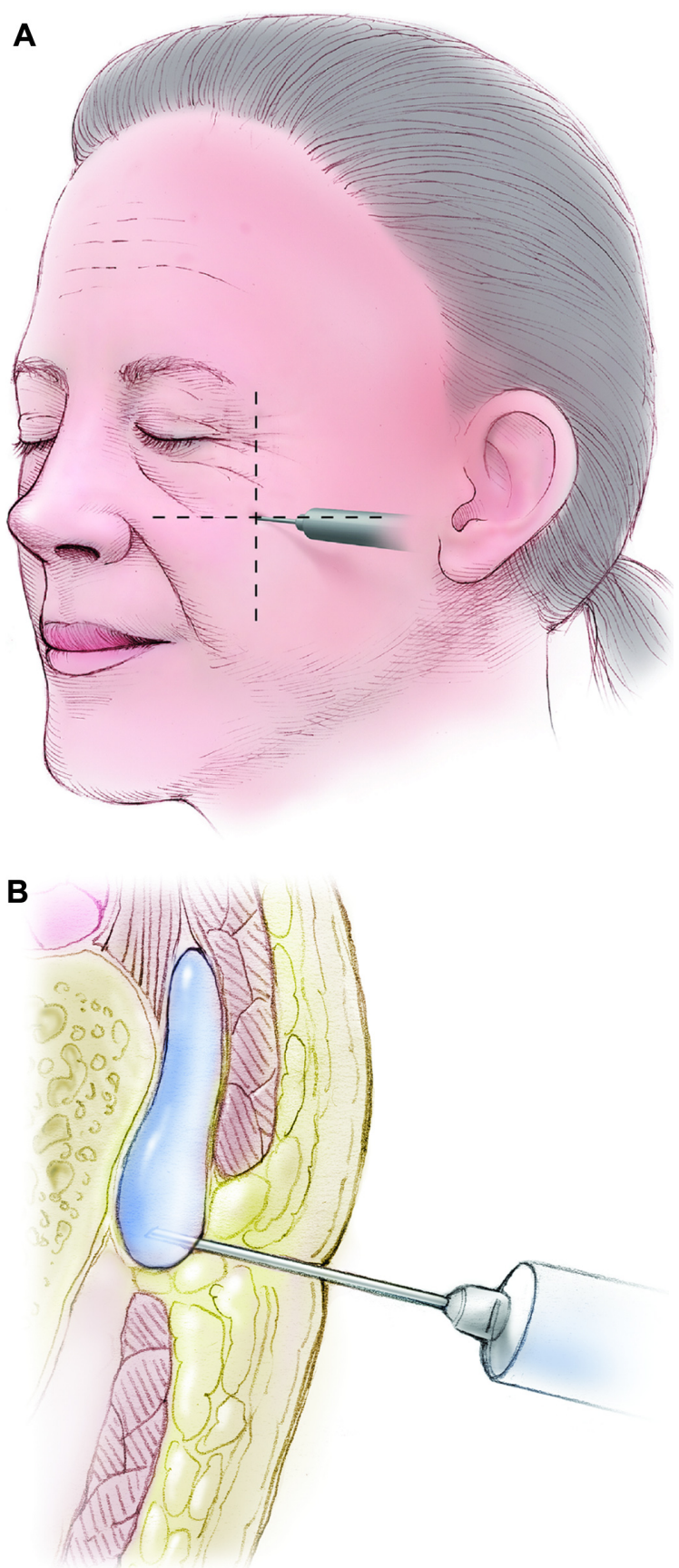

Figure 3 Creation of a youthful cheek apex at Swift's point. (A) Swift's point is defined as the intersection of a line drawn from the nasal alar groove to the upper tragus and the line drawn vertically down from the midpoint of the lateral orbital rim. (B) Injection for deep hyaluronic acid is overlying bone and periosteum and below muscle where possible.

Note: Subcutaneous injections can be performed with hyaluronic acid over the foundation injection as well.

Images provided by Allergan, Inc (Irvine, CA).

patients require appropriate counsel and education to clearly evaluate the limitations of a two-dimensional approach to reducing the appearance of lines and wrinkles in sufficiently creating a more youthful appearance. Initially the benefits of volume restoration may not be clear or appealing to the 
patient. By way of explanation, it is not uncommon to receive complaints focusing on deepening nasolabial folds rather than the responsible cheek volume loss that requires primary treatment. Furthermore, the media has sensationalized and sensitized potential candidates to the undesirable result of over-inflation. Hence, a thorough presentation and education to the patient detailing the rationale behind appropriate and natural volumization as part of the comprehensive treatment is always necessary as a preface to acceptance.

Patient selection is based on the receptivity of each patient to the education provided on the most optimal plan to achieve desired results. The following section provides guidance on the most critical areas to focus the education such that the patient is informed and aware of the anticipated results if the proposed plan, including volume restoration, and timeline are followed. In all patient consultations, ample information is proactively shared to address the potential risks associated with each of the treatments in the proposed plan. Following the prescribed time to provide counsel to each patient, correct any misconceptions of the procedure(s) required to achieve results and gain agreement on the proposed treatment plan, the patient is selected as a candidate that may have a positive outcome and experience with facial rejuvenation.

High-quality clinical photographs remain an essential component to all aesthetic procedures, both surgical and non-surgical. A dedicated photography suite with consistent lighting and high resolution photographic equipment can offer reproducible images for validation of aesthetic results with patients, for marketing and for teaching purposes.

\section{Patient education critical to avoiding perceived adverse events}

The following list provides guidance on the most optimal patient communication strategies to clearly prepare the patient for the requirements to achieving 'the desired outcome'. As indicated previously in the review, the most common adverse outcome relates to the misperception among patients on what is involved in the rejuvenation process, ie, the necessity to incorporate volume restoration in the strategy.

- Clearly explain and demonstrate that facial aesthetic practices changed from a line-chasing, two-dimensional approach to a global, three-dimensional approach with volume restoration and contouring at its core

- Take the time to comprehensively educate the patient about the principles behind and the benefits of volume restoration; use the example of cheek volume restoration to reduce the appearance of the nasolabial fold (NLF)

- Proactively address patient concerns or questions:

- Correct patient opinion that line effacement is sufficient

- Overcome the sensationalized media approach to volume restoration: Re-assure patient that 'volume restoration' does not mean a 'fat' face

- Ensure that the patient understands that undercorrection or "piece meal" correction often results in less satisfying outcomes

- Instruct patients to bring a photograph of themselves in their twenties; this will clearly highlight the areas where volume loss has occurred and more easily allow the physician to demonstrate that restoring lost volume is essential to restore a youthful appearance. One can also demonstrate specific aesthetic deficiencies present at an even younger age that can be addressed with appropriate treatment. Thus, one can discuss beautification as well as rejuvenation.

- Show before and after photographs of other patients demonstrating the effects of volume restoration on specific areas, always reinforcing that individual treatments and results vary

- Explain that optimizing results is a process that may require several sessions

- Educate clinic staff to be effective ambassadors for volume restoration and contouring

- Stress the synergistic benefits of combining soft tissue fillers with neuromodulators and non-invasive technology Prior to the injection, diligent patient skin prepping should be undertaken to minimize the risks associated with longerlasting products and the potential development of biofilm.

\section{Treatment specifics - method}

The following tables detail volume restoration and practices currently utilized (see Tables 2-4 and Figure 4).

For the purposes of treatment discussion, the face is divided into three fundamental, but overlapping sections: Mid, upper and lower. However, the global, whole-face and three-dimensional approach must always be the physician's primary consideration. Treatment is always carried out in the context of how it will integrate with the rest of the face, both at the moment of implementation and over time, taking changing facial dynamics into consideration.

It should be noted that these are recently developed procedures representing the collective experience and best practices of the authors at the time of writing and should not be construed as absolute, validated directives. It is important 


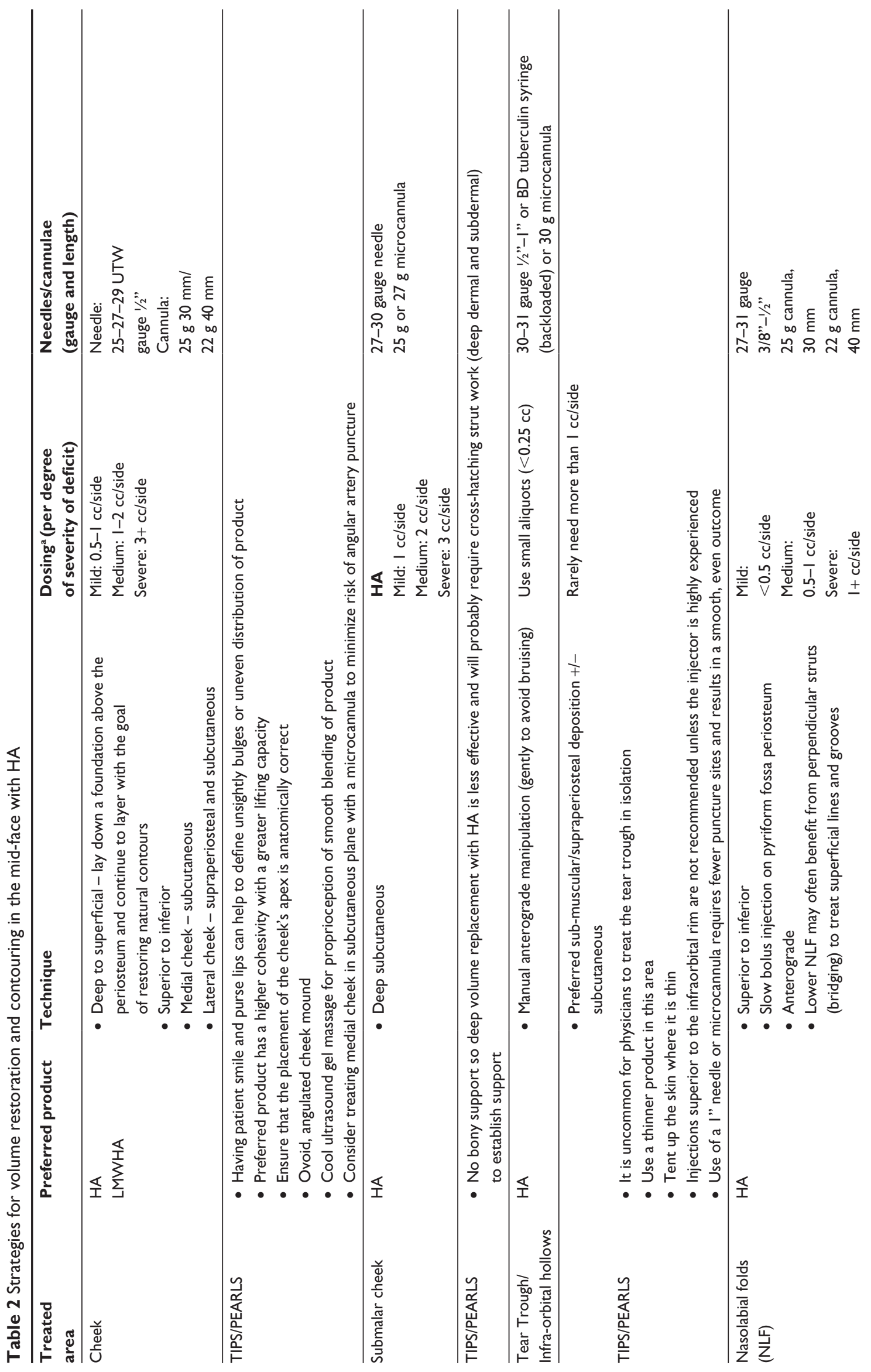


that each individual be treated uniquely while keeping these general principles in mind.

\section{Emerging trends for hyaluronic acid and the future of volume restoration and contouring}

In a discussion of emerging trends related to Volume Restoration, the authors identified several new practices and techniques that may become more widespread as patient awareness and physician experience increase.

\section{Earlobe volume}

The authors reported more use of hyaluronic acid to restore earlobe volume. The earlobe tends to sag and develop creases with age and was identified as an area that patients are increasingly eager to rejuvenate.

\section{Temporal hollow}

The temporal hollow is a significant manifestation of aging, which is currently undertreated. The authors predict that physicians and patients will come to appreciate the dramatic degree of improvement that can be achieved by restoring volume in the temporal hollow and that this practice will come to be incorporated as a mainstay of overall facial rejuvenation.

\section{Forehead}

One of the authors (AS) has reported an excellent aesthetic improvement in restoring a gentle convex curve to the forehead by the injection of subgaleal hyaluronic acid. The treatment goal is to create a gentle ogee curve from the hairline to the supraorbital prominence laterally and glabella region centrally in order to beautify the younger patient and rejuvenate the older. This addresses the definite loss of volume seen at all levels (subcutaneous, muscle and bone) in this area as we age.

\section{Future trends}

It was agreed that there were definable advantages to treating patients over several sessions and at multiple layers. These included economic considerations, optimization of results, longevity of product as well as affording patients the time to adjust to the aesthetic changes.

There is also likely to be increased focus on refining objective standards of beauty, based on mathematical determination of facial feature inter-relationships, balance and proportion which will educate patients and guide physician treatments. It is incumbent upon the aesthetic physician to 


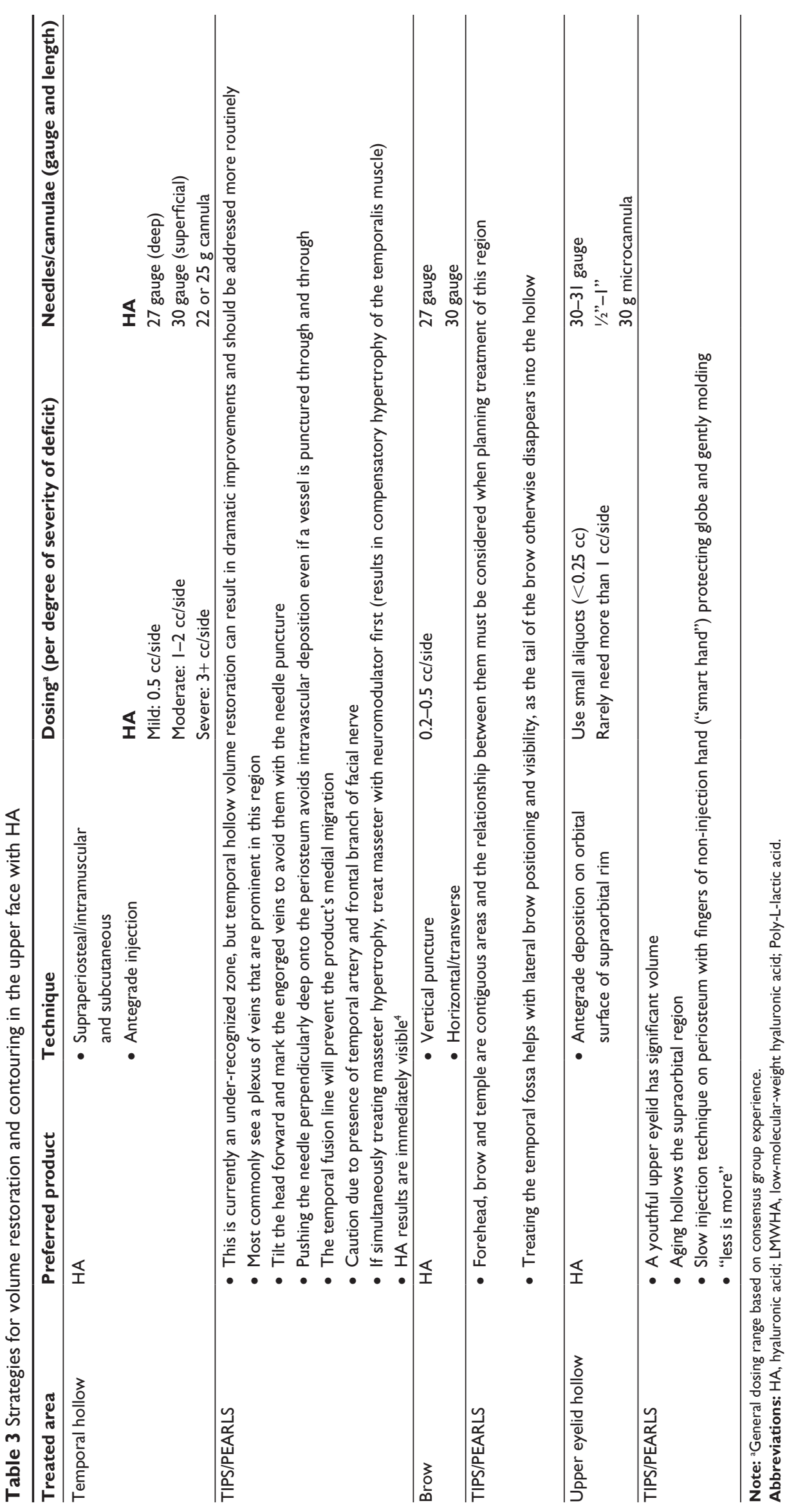


Table 4 Strategies for volume restoration and contouring in the lower face with HA

\begin{tabular}{|c|c|c|c|c|}
\hline Treated area & Preferred product & Technique & $\begin{array}{l}\text { Dosing (per degree of } \\
\text { severity of deficit) }\end{array}$ & $\begin{array}{l}\text { Needles/cannulae } \\
\text { (gauge and length) }\end{array}$ \\
\hline Chin & LMWHA/HA & $\begin{array}{l}\text { - Layering technique } \\
\text { - Inject on periosteum for lift and fill } \\
\text { - Subcutaneous injection to correct } \\
\text { irregularities }\end{array}$ & $\begin{array}{l}\text { HA } \\
\text { Mild: I cc } \\
\text { Moderate: } 2 \mathrm{cc} \\
\text { Severe: } 3 \mathrm{cc}\end{array}$ & $\begin{array}{l}27-30 \text { gauge } \\
1 / 2 " \\
22 \text { or } 25 \mathrm{~g} \\
\text { cannula }\end{array}$ \\
\hline TIPS/PEARLS & \multicolumn{4}{|c|}{$\begin{array}{l}\text { - Chin continues to pre-jowl sulcus and must blend into this area } \\
\text { - In all cases, consider a neuromodulator to treat the "apple core" chin, mental crease and to increase the longevity } \\
\text { of the HA } \\
\text { - Volume is usually necessary over the entire chin zone extending into the NL as well as the pre-jowl sulcus (PJS) }\end{array}$} \\
\hline Pre-jowl sulcus/marionette & LMWHA/HA & - Deep on bone and subcutaneous & $\begin{array}{l}\text { HA } \\
\text { Mild: } \\
0.5 \mathrm{cc} / \text { side } \\
\text { Moderate: } \\
\text { I cc/side } \\
\text { Severe: } \\
2+\mathrm{cc} / \mathrm{side}\end{array}$ & $\begin{array}{l}27-30 \text { gauge } \\
1 / 2 "-1 " \\
22 \text { or } 25 \mathrm{~g} \\
\text { cannula }\end{array}$ \\
\hline TIPS/PEARLS & \multicolumn{4}{|c|}{$\begin{array}{l}\text { - Have the patient sit vertically ( } 90 \text { degrees) so that the lower face is accentuated (fewer re-touches required) } \\
\text { - Palpability of product may be increased in this area (patient should be informed beforehand); consider manual } \\
\text { manipulation to avoid this } \\
\text { - Only soft tissue around the mouth; no bony prominence to lay the product on } \\
\text { - Caution not to masculinize the female face }\end{array}$} \\
\hline $\begin{array}{l}\text { Post jowl sulcus, mandibular } \\
\text { angle and preauricular }\end{array}$ & LMWHA/HA & - Deep subcutaneous & $\begin{array}{l}\text { HA } \\
\text { Mild: } \\
\text { I-2 cc/side } \\
\text { Moderate: } \\
\text { 2-3 cc/side } \\
\text { Severe: } \\
3-4 \mathrm{cc} / \mathrm{side}\end{array}$ & $\begin{array}{l}27 \text { gauge } \\
1 / 2-11 / 2 " \\
22 \mathrm{~g} \text { or } 25 \mathrm{~g} \\
\text { cannula }\end{array}$ \\
\hline TIPS/PEARLS & $\begin{array}{l}\text { - Caution not to ma } \\
\text { - Do not inject into } \\
\text { - Mold, blend and fe }\end{array}$ & $\begin{array}{l}\text { ulinize the face } \\
\text { e parotid gland } \\
\text { er }\end{array}$ & & \\
\hline
\end{tabular}

Note: a'General dosing range based on consensus group experience.

Abbreviations: HA, hyaluronic acid; LMWHA, low-molecular-weight hyaluronic acid.

remain current with constantly evolving beauty trends that are influenced by social and cultural ideology, as well as media perspective.

Combination treatment of fillers, neuromodulators and energy devices to create optimal contours is forecast to remain the mainstay of non-surgical facial aesthetics.

Further advances are expected to standardize techniques, increase reproducibility and consistency of results, and augment patient experiences by minimizing bruising and downtime.

\section{Overall summary and conclusions}

This is an exciting and prolific period in facial aesthetics: significant technological advances in products and techniques are resulting in more optimal patient outcomes with a corresponding increase in satisfaction rates.

The governing principle of non-surgical facial aesthetics today is an integrated consideration and treatment of the face as a global, inter-dynamic unit. This represents a dramatic shift from the previous two-dimensional monotherapy approach. Central to this three-dimensional paradigm is the restoration of lost volume of underlying soft and bony facial foundation structures; re-contouring in accordance with ideal aesthetic proportions; reestablishing pleasing ogee curves pan-facially; refining and shaping facial features; and softening lines, folds and grooves. The combination of facial fillers, neuromodulators, nonsurgical energy devices and surgical aesthetic procedures should also be considered for best results and a truly comprehensive treatment.

Soft-tissue fillers have become the mainstay for facial volume restoration and excellent newer products have recently become available. Canadian physicians, having access to a wide range of these newer materials, have pioneered many important techniques representing significant advances in the field. In particular, the availability of high-viscosity LMW hyaluronic acid has made it possible 


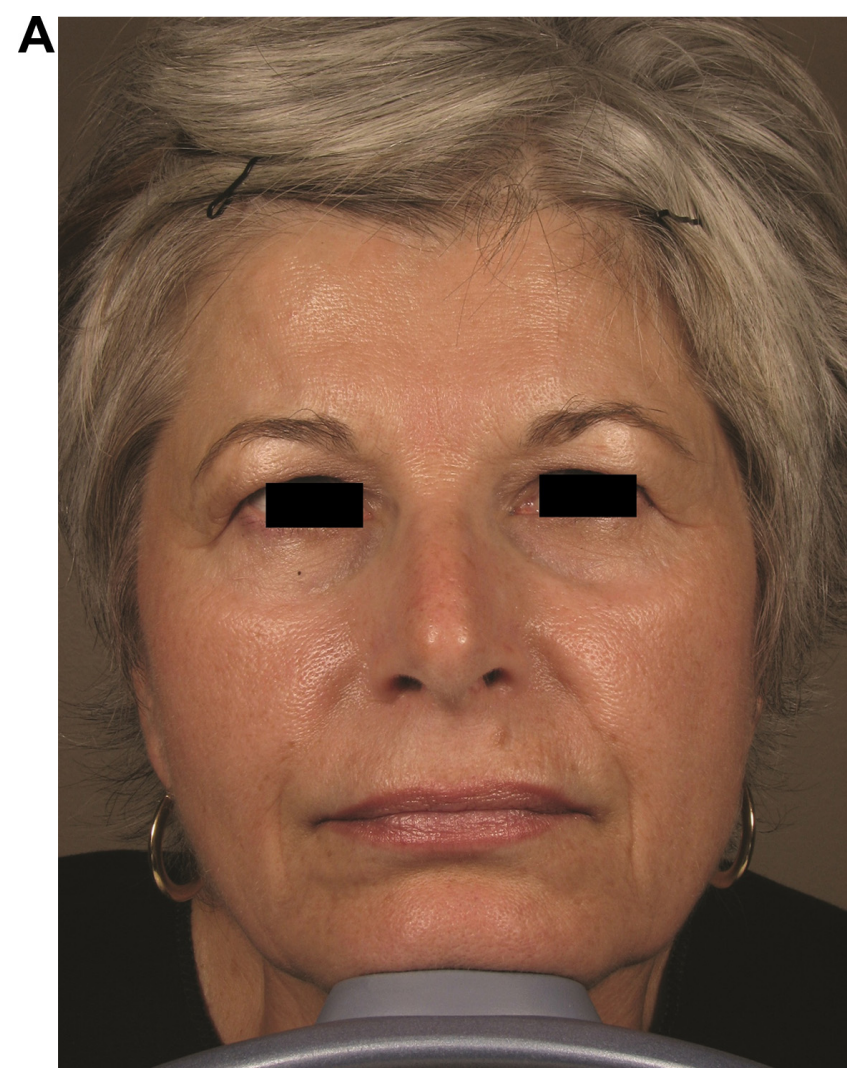

\section{B}
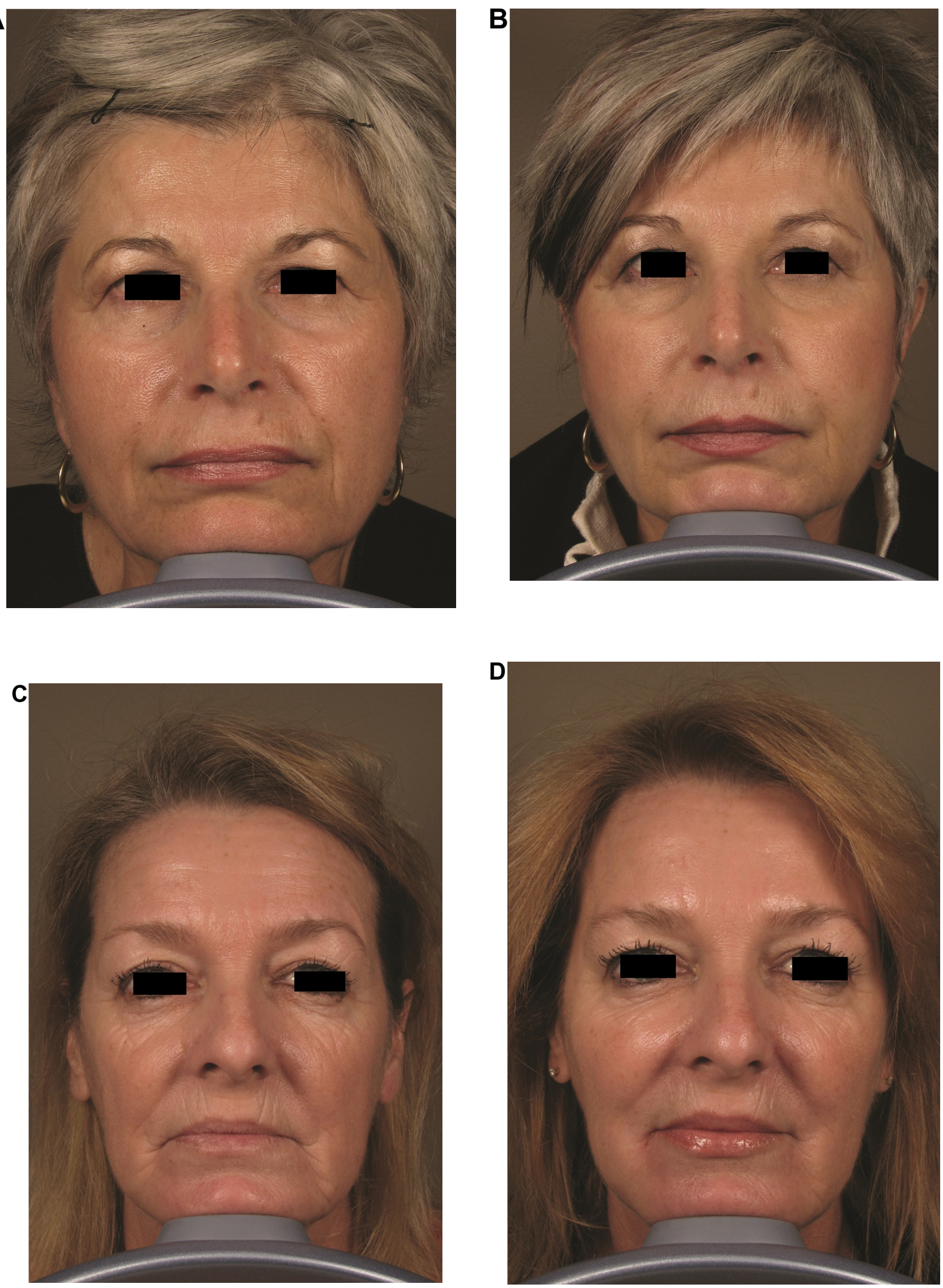

Figure 4 (Continued) 

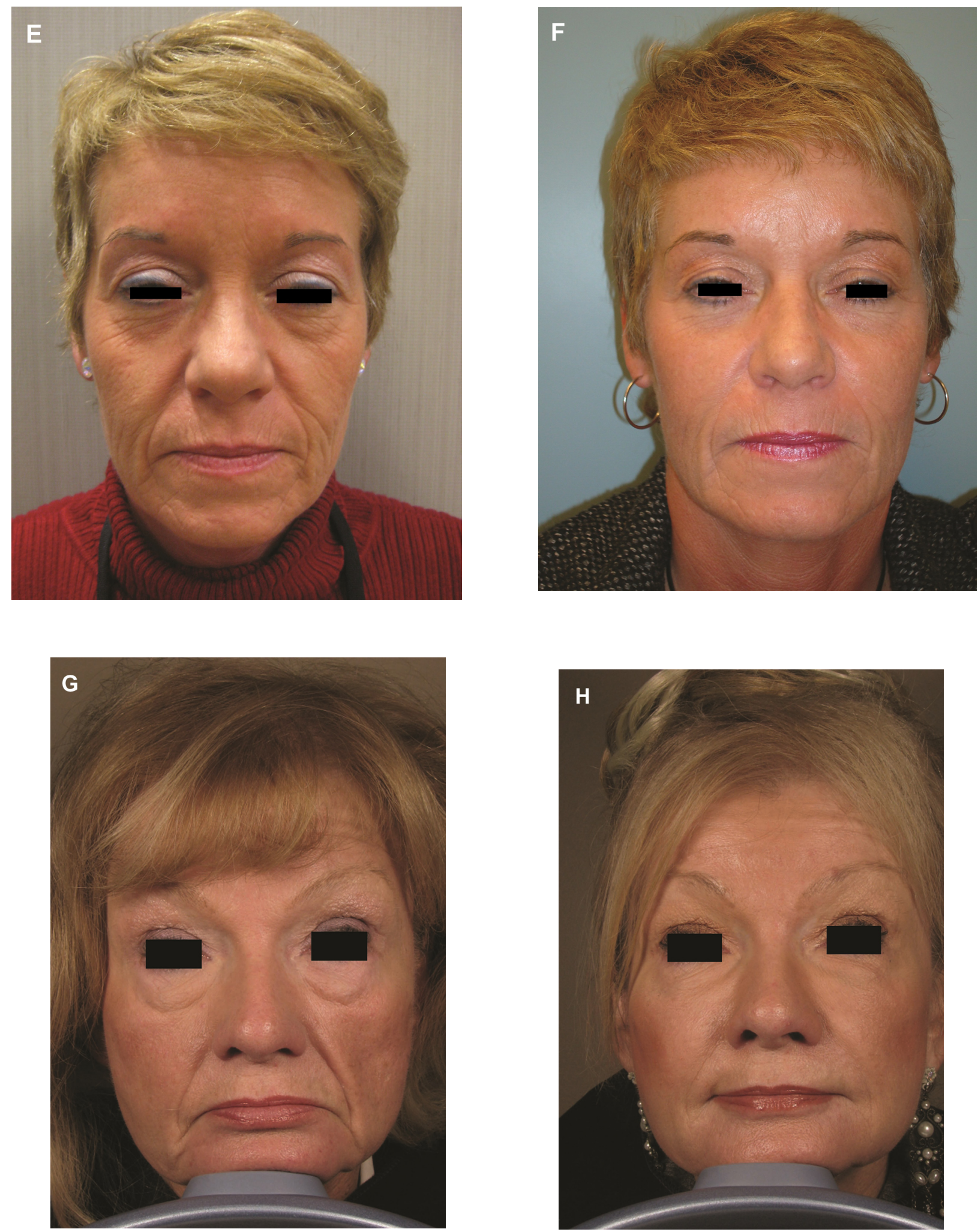

Figure 4 Before and immediately after volume restoration using high-viscosity, low-molecular-weight hyaluronic acid, hyaluronic acid, and onabotulinumtoxinA. Before (A) and after (B) volume restoration using $18 \mathrm{mg} / \mathrm{mL}$ gel hyaluronic acid filler, as well as onabotulinumtoxinA for glabellar frown lines and lateral brow. Before (C) and after (D) volume restoration using $24 \mathrm{mg} / \mathrm{mL}$ smooth gel hyaluronic acid filler and $24 \mathrm{mg} / \mathrm{mL}$ gel filler, as well as onabotulinumtoxinA for eyebrows, glabella, and crow's feet. Before (E) and after (F) volume restoration using $20 \mathrm{mg} / \mathrm{mL}$ smooth, high-viscosity, low-molecular-weight hyaluronic acid for the cheeks, nasolabial folds, and prejowl sulcus. Before (G) and after (H) volume restoration using $24 \mathrm{mg} / \mathrm{mL}$ smooth gel hyaluronic acid fillers and $24 \mathrm{mg} / \mathrm{mL}$ gel filler.

Photos (A) and (B) courtesy of Dr Nathan Rosen; photos (C) and (D) courtesy of Dr Channy Muhn; photos (E) and (F) courtesy of Dr Fred Weksberg; photos (G) and (H) courtesy of Dr Channy Muhn. 
for physicians to achieve new levels of excellence in facial aesthetics. In clinical practice, the authors have demonstrated that high-viscosity LMWHA has advantages when used for volume restoration and contouring, including versatility of use (different facial planes), high malleability, minimal swelling, limited downtime, and immediate patient satisfaction.

\section{Acknowledgments/disclosure}

This activity was supported by an educational grant provided by Allergan, Inc. Drs Muhn, Rosen, Solish, Bertucci, Lupin, Dansereau, Weksberg, Remington and Swift are consultants for Allergan, Inc. Editorial support was provided by IntraMed.

\section{References}

1. Coleman SR, Grover R. The anatomy of the aging face: volume loss and changes in 3-dimensional topography. Aesthet Surg J. 2006;26(1S):S4-S9.

2. Rohrich RJ, Pessa JE. The fat compartments of the face: anatomy and clinical implications for cosmetic surgery. Plast Reconstr Surg. 2007;119(7):2219-2227.

3. Carruthers JD, Glogau RG, Blitzer A; for Facial Aesthetics Consensus Group Faculty. Advances in facial rejuvenation: botulinum toxin type a, hyaluronic acid dermal fillers, and combination therapies-consensus recommendations. Plast Reconstr Surg. 2008;121(Suppl 5):5S-30S; quiz $31 \mathrm{~S}-36 \mathrm{~S}$.
4. Goldberg DJ. Breakthroughs in US dermal fillers for facial soft-tissue augmentation. J Cosmet Laser Ther. 2009;11(4):240-247.

5. Raspaldo H. Volumizing effect of a new hyaluronic acid sub-dermal facial filler: a retrospective analysis based on 102 cases. J Cosmet Laser Ther. 2008;10(3):134-142.

6. Hoffmann K; for Juvéderm Voluma Study Investigators Group. Volumizing effects of a smooth, highly cohesive, viscous $20-\mathrm{mg} / \mathrm{mL}$ hyaluronic acid volumizing filler: prospective European study. $B M C$ Dermatol. 2009;27;9(9):1-9.

7. Graivier MH, Bass LS, Busso M, Jasin ME, Narins RS, Tzikas TL. Calcium hydroxylapatite (Radiesse) for correction of the mid - and lower face: consensus recommendations. Plast Reconstr Surg. Nov 2007;120(Suppl 6):55S-66S

8. Burgess CM. Principles of soft tissue augmentation for the aging face. Clin Interv Aging. 2006;1(4):349-355.

9. John HE, Price RD. Perspectives in the selection of hyaluronic acid fillers for facial wrinkles and aging skin. Patient Prefer Adherence. 2009;3:225-230.

10. Tezel A, Fredrickson GH. The science of hyaluronic acid dermal fillers. $J$ Cosmet Laser Ther. 2008;10(1):35-42.

11. Solish N, Beer K. Hyaluronic acids: basic science. In: Jones D, editor. Injectable Fillers: Principles and Practice. Oxford: WileyBlackwell; 2010:19-26.

12. James J, Carruthers A, Carruthers J. HIV-associated facial lipoatrophy. Dermatol Surg. 2002 N;28(11):979-986.

13. Jones D, Flynn TC. Hyaluronic acids: clinical applications. In: Jones D, editor. Injectable Fillers: Principles and Practice. Oxford: Wiley-Blackwell; 2010:158-174.

14. Meneghini F, editor. Clinical Facial Analysis: Elements, Principles and Techniques. New York: Springer-Verlag; 2005.
Clinical, Cosmetic and Investigational Dermatology

\section{Publish your work in this journal}

Clinical, Cosmetic and Investigational Dermatology is an international, peer-reviewed, open access, online journal that focuses on the latest clinical and experimental research in all aspects of skin disease and cosmetic interventions. All areas of dermatology will be covered; contributions will be welcomed from all clinicians and

\section{Dovepress}

basic science researchers globally. This journal is indexed on CAS The manuscript management system is completely online and includes a very quick and fair peer-review system, which is all easy to use. Visit http://www.dovepress.com/testimonials.php to read real quotes from published authors. 